\title{
Summer diet composition of the Common Leopard Panthera pardus (Carnivora: Felidae) in Nepal
}

\author{
Achyut Aryal ${ }^{1}$ \& Brigitte Kreigenhofer ${ }^{2}$ \\ 1,2 Ecology \& Conservation Group, Institute of Natural Sciences, Massey University, New Zealand \\ ${ }^{1}$ The Biodiversity Research and Training Forum (BRTF), Nepal \\ Email: ${ }^{1}$ a.aryal@massey.ac.nz, savefauna@yahoo.com
}

Date of publication (online): 26 November 2009 Date of publication (print): 26 November 2009 ISSN 0974-7907 (online) | 0974-7893 (print)

Editor: Weihong Ji

\section{Manuscript details:}

Ms \# 02287

Received 19 August 2009

Final received 30 October 2009

Finally accepted 01 November 2009

Citation: Aryal, A. \& B. Kreigenhofer (2009) Summer diet composition of the Common Leopard Panthera pardus (Carnivora: Felidae) in Nepal. Journal of Threatened Taxa 1(11): 562-566.

Copyright: $\odot$ Achyut Aryal \& Brigitte Kreigenhofer 2009. Creative Commons Attribution 3.0 Unported License. JoTT allows unrestricted use of this article in any medium for non-profit purposes, reproduction and distribution by providing adequate credit to the authors and the source of publication

Author Details: Achrut ARYal is a PhD student at Massey University, New Zealand. He is working on conservation biology of Blue Sheep and Snow Leopard in Nepal for his $\mathrm{PhD}$ dissertation. BrigitTe Kreigenhofer is MSc student at Massey University, New Zealand.

Author Contribution: AA is main author. BK assisted in editing.

Acknowledgments: We are grateful to our supervisors Prof. Dr. Ilse Storch, Prof. Dr. Dieter R. Pelz (Faculty of Forest and Environment Sciences, Albert Ludwigs University of Freiburg, Germany) and Dr. S. Sathaykumar (WII, India) for their impressive tutelage, constructive criticism and intellectual support to complete the study. We would like to acknowledge Dr. Som Ale for his support and Department of National Park and Wildlife Conservation for directing and suggesting in several ways to getting permission and their encouragement and Dr. Rinjan Shrestha (WWF, Nepal) for his encouragement and support to field study. We would like to acknowledge Snow Leopard Conservation Grants Program for granting financial support to this research work and Wildlife Institute of India for providing training on carnivores' diet analysis.

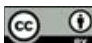

(10)

OPEN ACGESS | FREE DOWNLOAD
Abstract: The Common Leopard Panthera pardus is one of the most widely distributed of all big cats. It is a threatened species throughout its range due to the degradation of natural habitat, poaching and persecution as a killer of humans and livestock. The purpose of this study was to determine the composition of the Common Leopard diet in the Dhorpatan Hunting Reserve (DHR) of Nepal. Among prey species Barking Deer (Muntiacus muntjak) were observed most frequently $(18 \%)$ in leopard scats, while Blue Sheep (Pseudois nayaur) were observed less frequently $(6 \%)$.

Keywords: Dhorpatan Hunting Reserve, diet composition, leopard, predators, prey.

\section{INTRODUCTION}

The Common Leopard Panthera pardus is one of the most widely distributed of all big cats (Bailey 1993), occupying an array of habitats in Asia and Africa. In south Asia, it is found in Pakistan, India, Nepal, Sri Lanka and Indochina (Prater 1993; Shrestha 1997). As a habitat generalist species (Bailey 1993; Maan \& Chaudary 2000), the leopard can live and thrive in almost all types of habitats including dense forest, rock and scrub (Prater 1993), grasslands and even on mountain cliffs, where sufficient hideouts and prey species are available (Bailey 1993). Its behaviour varies according to the habitat it occupies (Seidensticker et al. 1990; Bailey 1993; Daniel 1996). These leopards have such a diverse and wide distribution due to their highly adaptable hunting and feeding practices, and their solitary nature. They can easily survive in human dominated areas by changing their dietary habits to include livestock, dogs and humans (Gugginsberg 1975; Sedeinsticker et al. 1990; Daniel 1996; Chauhan \& Goyal 2001). The Leopard is categorised as a Near Threatened species by the IUCN Red List of Threatened Species (Henschel et al. 2008). It is threatened throughout its range due to habitat degradation, poaching for its valuable skin and bone, and persecution as a killer of humans and livestock. The ecology of the leopard in south Asia is not fully understood. However, some studies have been carried out in the region (Eisenber \& Lokhart 1972; Sunquiist 1983; Seidensticker et al. 1990). The ecology and behaviour of this elusive species cannot be fully understood without knowing how leopards respond to various ecological resources and disturbance scenarios. Therefore, this study was carried out to understand the dietary composition of Common Leopards in the Dhorpatan Hunting Reserve of Nepal. Scat samples were collected during the summer season (March to June) of 2008. Blue Sheep Pseudois nayaur is the main legally hunted species in the reserve and is also assumed to be the main prey species of Common Leopards and other predator species as well, such as the Snow Leopard. Blue Sheep are assumed as the main prey species of Snow Leopards and other predators within the high altitude biomes of Eurasia. They are a species that are trophy hunted in DHR and the conservation of Blue Sheep is of international and national concern given its keystone prey status. Therefore, the main objective of this study was to determine the proportion of the Common Leopard diet that consists of Blue Sheep during the summer.

\section{Methods and Materials}

Study Area: This study was carried out in the Phagune and Barse blocks of the Dhorpatan Hunting Reserve of Nepal (Fig. 1). This reserve, which is divided into seven blocks, lies in the Baglung District in the Dhaulagiri Himalaya of western Nepal $\left(23^{\circ} 30^{\prime}-28^{\circ} 50^{\prime} \mathrm{N} \& 82^{\circ} 50^{\prime}-83^{\circ} 15^{\prime} \mathrm{E}\right)$. It covers an area of $1325 \mathrm{~km}^{2}$ with altitude ranging from $2,850 \mathrm{~m}$ to $5,500 \mathrm{~m}$. (Wegge 1979).

Phagune: In the west along the trail north from Uttar Ganga at Taka across the Phagune ridge at approximately $3800 \mathrm{~m}$; down to Pelma khola, there turning east 


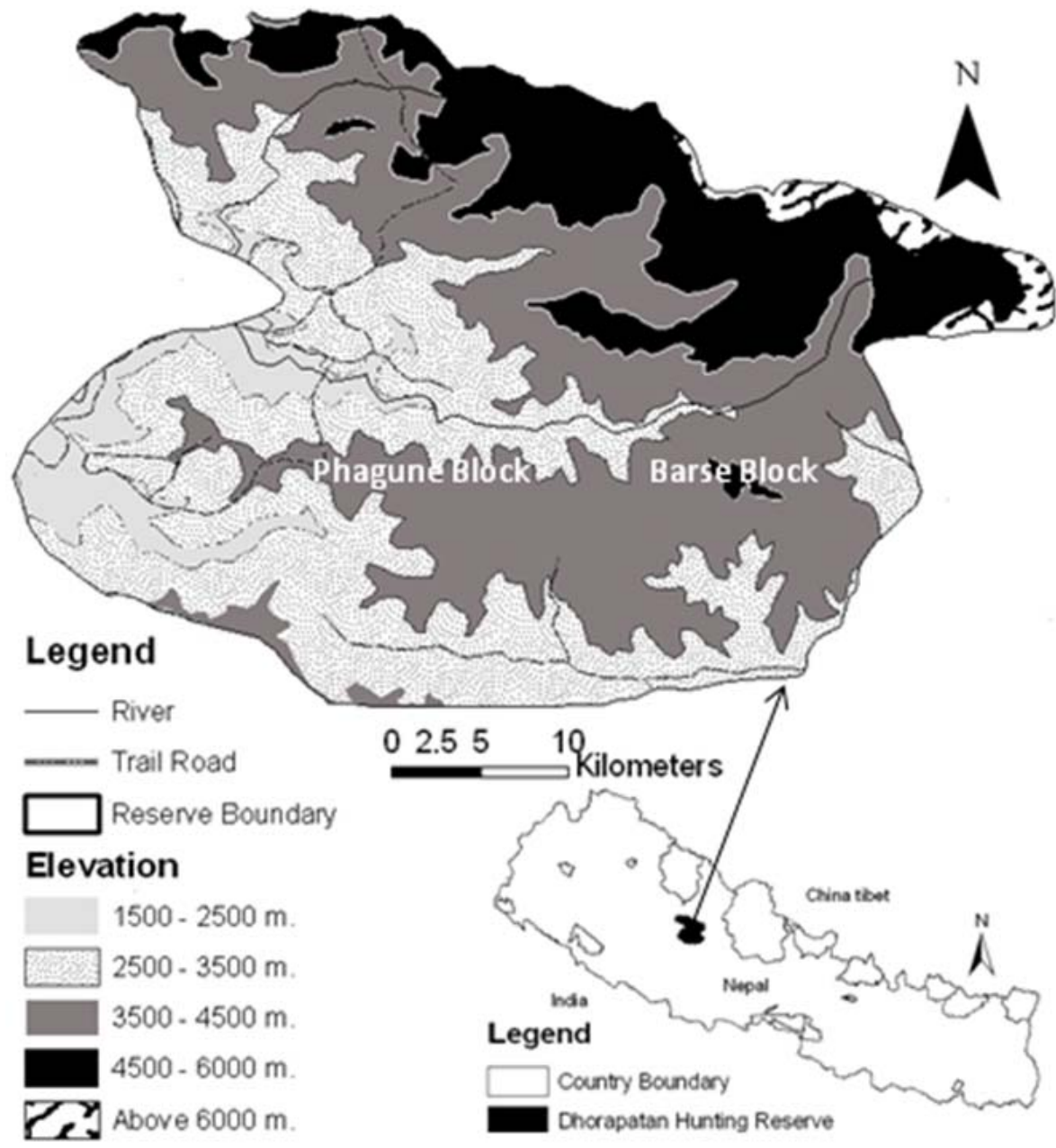

Figure 1. Study area (with Phagune and Barse blocks)

upstream along Pelma and Gustung kholas to an about $3.2-4.0 \mathrm{~km}$ east sheep ridge east of tributary, along east side of the ridge to the Dhorpatan trail intersection than following trail south to Dhorpatan and back down along Uttar Ganga

Barse: Along the eastern part of Phagune block, southwards along the Kharka trail to Dhorpatan, eastwards along Uttar Ganga to Barse Mount trail take-off, following trail along the ridge northwards across pass to eastern tributary of Gustung Khola, along the tributary and Gustung down back to Phagune block boundary (Wegge 1979).

Climate: The reserve is located in front of a moderately high saddle connecting the high Dhaulagiri and Hiuchuli. It is also shielded by several lekhs (high altitude grassland) South of Uttar Ganga. The sheep area therefore receives less precipitation than others areas of the Nepal midlands (Stainton 1972). Wegge (1976) extrapolates the annual precipitation to somewhat less than $1000 \mathrm{~m}$.

Vegetation: The area is characterized by many plant species of the drier climatic belt to the north, but remnants of the more humid zone are also present, giving the area a mixed vegetation cover. Falling in a transition zone, the dry northern elements are more pronounced at higher altitudes and on south-easterly aspects. In more moist and shaded habitats mixed hardwoods form well-developed strands at lower elevation, yielding first to Fir Abies spectabilis and then to birch/rhododendron at higher altitudes. The upper northern slopes are densely covered with Birch Betula utilis and Rhododendron Rhododendron campanulatum to the tree line, between 3,050m and 3,660m; below is a belt of Fir and Hemlock Tsuga dumosa, which gives way to a rich mixed-hardwood forest next to the river. The southern slopes, on the contrary, in a wide belt from approximately $3,500 \mathrm{~m}$ to $2,440 \mathrm{~m}$, consist of a very sparse scrub forest of Oak Quercus semecarpifolia, interspersed with isolated Blue Pine Pinus excelsa trees and occasionally Rhododendron Rhododendron arboreum.

Fauna: Dhorpatan is noted for its Blue Sheep population. Other ungulates include Goral Nemorhaedus goral, Himalayan Tahr Hemitragus jemlahicus, and Wild Boar Sus scrofa (particularly common in the upper coniferous zone, especially in the Gurbad and Uttar Ganga catchments), Himalayan Musk Deer Moschus chrysogaster (widely distributed), Serow Capricornis sumatraensis and Indian Muntjac Muntiacus muntjak. The Leopard is common and widely distributed up to altitudes of $4,420 \mathrm{~m}$. Other predators include Lynx Felis lynx (known to occur in the Upper Seng Valley). Wild Dog Cuon alpinus, Red Fox Vulpes vulpes, Wolf Canis lupus and Snow Leopard Uncia uncia are occasional visitors to the area. Himalayan Black Bear Selenarctos thibetanus is common in forested areas. Red Panda Ailurus fulgens is reported to be fairly common in the upper forests of the Lower Seng and Upper Bakre valleys (Wegge 1976; Fox 1985).

Common Leopard scat survey: Sign (scats, pugmarks, scraping and scent spray) surveys were carried out in the study area to distinguish different predators' scats and to estimate scat density. The signs of different predator species were identified on basis of their size, colour, pugmarks and other features (Table 1). Wild Dog and Lynx scats were avoided because herders and livestock were downhill, and we did not find evidence of Lynx or Wild Dogs in the Barse and Phagune blocks. Furthermore, it was assumed that scats found above $4500 \mathrm{~m}$ in altitude were left by Snow Leopards and/or Wolves. Common Leopard scats were collected below $4500 \mathrm{~m}$. All together, 147 Common Leopard scats were collected from the field for diet analysis. The survey covered $265 \mathrm{~km}^{2}$ of Barse and Phagune block of study area.

Scat collection and analysis methods: Eighty-one existing human and livestock trails, each $1.5 \mathrm{~km}$ in length, were used as transect lines for the collection of the faecal material of various predators. A total of $121 \mathrm{~km}$ was sampled with the highest elevation reached being 4,500m. Following scats collection, a standard micro-histological method was used to identify prey species through the hair samples found in the Common Leopard scat. Species identification was accomplished by comparing the hairs 
Table 1. The distinguishing characteristics of different predator signs that were used to confirm the presence of various species

\begin{tabular}{|c|c|c|c|c|c|}
\hline Feature & Common Leopard & Snow Leopard & Wolf & Red Fox & Civet \\
\hline \multirow[t]{3}{*}{ Scats } & $\begin{array}{l}\text { (i) Scats are deposited alone or in } \\
\text { association with other signs. }\end{array}$ & $\begin{array}{l}\text { (i) Scats are deposited alone or in } \\
\text { association with other signs. }\end{array}$ & $\begin{array}{l}\text { (i) Canid scats tend } \\
\text { to be long with } \\
\text { tapered ends, } \\
\text { compared to felid } \\
\text { scats. }\end{array}$ & $\begin{array}{l}\text { (i) Scats are smaller } \\
\text { in size, long and } \\
\text { final tips pointed. }\end{array}$ & $\begin{array}{l}\text { (i) Civet scats are } \\
\text { smaller than red } \\
\text { fox scats in both } \\
\text { size and quantity }\end{array}$ \\
\hline & (ii) Single scraping. & (ii) Scats are short and segmented. & $\begin{array}{l}\text { (ii) Scats are } \\
\text { deposited in a } \\
\text { group. }\end{array}$ & $\begin{array}{l}\text { (ii) Scats are found } \\
\text { on grasses and fruit } \\
\text { material. }\end{array}$ & \\
\hline & & & $\begin{array}{l}\text { (iii) Wolves tend to } \\
\text { make scratches } \\
\text { rather than scrapes. }\end{array}$ & & \\
\hline \multirow[t]{9}{*}{ Scrapes } & $\begin{array}{l}\text { (i) Scrapes can be oriented to trail in } \\
\text { any manner and can be found } \\
\text { either on or next to the trail. }\end{array}$ & $\begin{array}{l}\text { (i) Scrapes are oriented parallel to and } \\
\text { beside the trail. }\end{array}$ & & & \\
\hline & $\begin{array}{l}\text { (ii) Scrapes are clustered linearly } \\
\text { as long strings. }\end{array}$ & $\begin{array}{l}\text { (ii) Scrapes are clustered circular in a tight } \\
\text { group. }\end{array}$ & & & \\
\hline & (iii) Re-scraping is uncommon. & $\begin{array}{l}\text { (iii) Re-scraping of the same scrape or } \\
\text { cluster of scrapes is very common. }\end{array}$ & & & \\
\hline & $\begin{array}{l}\text { (iv) Scrape clusters appear } \\
\text { ephemeral rather than sculptured. }\end{array}$ & $\begin{array}{l}\text { (iv) Scrape clusters acquire a sculptured } \\
\text { appearance. }\end{array}$ & & & \\
\hline & $\begin{array}{l}\text { (v) A small pile of soil found behind } \\
\text { the scrape depression. }\end{array}$ & $\begin{array}{l}\text { (v) A large pile of soil found behind the } \\
\text { scrape depression. }\end{array}$ & & & \\
\hline & $\begin{array}{l}\text { (vi) Toe or claw indentations are } \\
\text { frequently found in scrape } \\
\text { depressions. }\end{array}$ & $\begin{array}{l}\text { (vi) Toe or claw indentations are rarely } \\
\text { found in the scrape depression Pugmarks } \\
\text { are rarely found at the front of the scrape } \\
\text { depression. }\end{array}$ & & & \\
\hline & $\begin{array}{l}\text { (vii) Scrapes appear to be hastily } \\
\text { made. }\end{array}$ & $\begin{array}{l}\text { (vii) Scrapes appear to have been made } \\
\text { with care. }\end{array}$ & & & \\
\hline & $\begin{array}{l}\text { (viii) Scrapes are longer, narrower, } \\
\text { and more linear in shape. }\end{array}$ & $\begin{array}{l}\text { (viii) Scrapes are broader, shorter, and more } \\
\text { heart shaped. }\end{array}$ & & & \\
\hline & (ix) Scrape depressions are shallow & $\begin{array}{l}\text { (ix) The scrape depressions are deeper than } \\
\text { the scrape of the Common Leopard. }\end{array}$ & & & \\
\hline Urine & & $\begin{array}{l}\text { Snow Leopards may urinate on the top of } \\
\text { their scrapes. }\end{array}$ & & & \\
\hline \multicolumn{2}{|l|}{ Scent spraying } & $\begin{array}{l}\text { Both sexes may scent mark upright rock } \\
\text { faces by spraying them with urine. }\end{array}$ & & & \\
\hline Claw -raking & & $\begin{array}{l}\text { Snow Leopards may leave claw marks on } \\
\text { tree trunks or rock faces. }\end{array}$ & & & \\
\hline Altitude & $<4500 m$ & $\begin{array}{l}\text { Generally scats found above } 4000 \mathrm{~m} \text { - } \\
4500 \mathrm{~m} \text {. It is assumed that scats found } \\
\text { above } 4500 \mathrm{~m} \text { are of Snow Leopards. }\end{array}$ & $>3000 m$ & $2500 m-4000 m$ & \\
\hline
\end{tabular}

Source: Jackson \& Hunter 1996

from the faecal samples to reference hair samples for each of the potential prey species in the area. Specifically, the surface scale patterns of the guard hairs were compared. Scats of different predators were identified based on size, colour, location, local knowledge and microscopic structure of the medulla and cuticle structure of the hairs.

Scat samples were prepared according to the methods described by Mukherjee et al. (1994). The hair samples were first washed in hot water and then thoroughly air dried. They were subsequently cleared in ether for one hour to remove wax deposits and any remaining moisture. Finally, the hairs were passed through Xylol for 24 hours and mounted on permanent slides with DPX to allow for the analysis of the medulla structure of the hairs. A gelatine solution was used to prepare slides for the analysis of the cuticle structure of hairs and cuticle scales were observed using impression techniques. The slides were observed under a light microscope (400x) and digital photos were taken so that the cuticle and medulla patterns could be observed. The main emphasis was placed on blue sheep hair so that the predators of this species could be identified. At least 20 hair samples were taken from each faecal sample for analysis and to allow for the detection of multiple prey species (Mukherjee et al. 1994). The prey residue composition of the predator scats was extrapolated in terms of the prey frequency of occurrence in the scat samples (Fi), calculated by equation-I (Pikunov \& Korkishko 1992; Karanth \& Sunquist 1995; Mizutani 1999; Ramakrishan et at. 1999).

$$
\mathrm{Fi}=(\mathrm{ni} / \mathrm{N}) 100 \quad \text { equation }(\mathrm{I})
$$

Where ni is the number of scats where a given ith prey species residue occurs and $\mathrm{N}$ is the total number of all scat 
Table 2. Occurrences of prey species (based on hair and other food) in Common Leopard scat (n-147)

\begin{tabular}{lll}
\hline Prey species & Frequency & $\%$ \\
\hline Barking Deer & 521 & 17.72 \\
Wild Boar & 430 & 14.63 \\
Pika & 287 & 9.76 \\
Other food item including & & \\
vegetation, soil \& stones & 264 & 8.98 \\
Himalayan Serow & 236 & 8.03 \\
Himalayan Musk Deer & 211 & 7.18 \\
Blue Sheep & 176 & 5.99 \\
Monkey & 109 & 3.71 \\
Vegetation & 109 & 3.71 \\
Goat & 83 & 2.82 \\
Birds & 75 & 2.55 \\
Goral & 69 & 2.35 \\
Cow & 44 & 1.50 \\
Unknown & 286 & 9.36 \\
Himalayan Tahr & 34 & 1.16 \\
Horse & 6 & 0.20 \\
\hline
\end{tabular}

samples.

\section{Results}

Dietary composition of Common Leopard: The frequency of occurrence of different prey species in the scat of common leopards in this region of Nepal is found in Table 2. There was no significant difference between the frequency of occurrence of different prey species and there was a positive correlation between each prey species and the Common Leopard $\operatorname{diet}\left(\chi^{2}=0.889, \mathrm{df}=16, \mathrm{p}>0.05 ; \mathrm{R}^{2}=0.84\right)$. Barking Deer was the most frequently occurring species (18\%) while only $6 \%$ of their diet consisted of Blue Sheep. The Common Leopards in this region also consumed Wild Boar, Himalayan Serow, Pika (Ochotona royleı), Musk Deer, and livestock, which made up approximately $4 \%$ of the collected faecal material (Table 2). Other food items, such as vegetation, soil, and stones, made up $9 \%$ of the total diet composition.

\section{Discussion}

Wegge (1976) originally reported Snow Leopards as a possible permanent resident in the northern reaches of the DHR (Wegge 1979; Wilson 1981). Local people reported that within the last 4 years snow leopards have been frequently visiting the northern part of the DHR, i.e. the Barse (Mansun area and northeastern site of Barse Duri), Gustung, Seng and Dhogadi blocks. These cats also visit the border of that lies between the Phagune and Barse blocks, which has been confirmed by both old ( $>5$ week) and fresh Snow Leopard scats found in this area. We were able to collect very low number of Snow Leopard scats in Mansun area and in Barse Duri. It is confirmed that snow leopards are not permanent residents in the Barse and Phagune blocks of DHR. However, there may be permanent snow leopard residents in the Gustung, Seng, and Dhogadi blocks of DHR but detailed studies should be carried out to confirm this. Common Leopards frequently visited areas up to $4500 \mathrm{~m}$ altitude. Therefore, it there may be food competition between Common Leopards, Snow Leopards and Wolves, which also inhabit these areas of high altitude.

It is evident that small mammals are very important in the Common Leopard diet as this study shows that about $10 \%$ of the diet of these Common Leopards consisted of Pika and $16 \%$ consisted of Wild Boars. Smaller mammals are an important component of predator diets (Zhirjakov 1990) and even more so when it's major or preferred prey is not readily available. The summer scats of Common Leopards mainly consisted of barking deer. Very little information is available on the importance of alternative prey in a predator's diet (Shaw 1977). The role of alternate prey becomes very important when the predator's major prey species is not readily available. In such a situation, alternate prey, in the form of smaller animals (e.g. Pika and Wild Boars), become a very important component in the Common Leopard's diet. This is obvious from Common Leopard food habitat, in the summer the Barking Deer was the major prey species of Common Leopards. However, Barking Deer move to dense forest area and may form groups as an antipredatory strategy. Pikas, which were abundant during the summer, then become the major prey species for various predators in the DHR. This dietary shift during the summer considerably reduces predation pressure on the other prey species. Another possible explanation for the increase in small mammal population was the decreasing the population of Wolves, which was assumed to be the major predator of these mammals. Therefore, the predation strategy of the Common Leopards shifts towards smaller mammals in the DHR.

Six percent of the Common Leopards' diet consisted of Blue Sheep. It thus seems that Common Leopards occasionally kill Blue Sheep during summer. In the continued predation pattern of above predators in the study area, if all the domestic prey is to be removed then the role of the alternate prey in the form of smaller animals will be of greater importance. The predation on smaller animals, especially Pika and Wild Boar, were so heavy that they were exterminated from some sites of Barse and Phagune blocks. Snow Leopards, Wolves, Common Leopards and Red Foxes are competitors and depend on almost the same type of prey species in the DHR. Therefore, the DHR management has to consider managing these species more scientifically and at the same time the Blue Sheep hunting quota should be determined through the scientific evaluation. The abundance and availability of alternate prey species will help maintain the Blue Sheep population on a sustainable basis.

\section{RefERENCES}

Bailey, T.N. (1993). The African Leopard: Ecology and Behaviour of Solitary Felid. Columbia University press, New York, USA, 429p.

Chauhan, D.S. \& S.P. Goyal. (2001). A study on distribution, relative abundance and food habits of leopards (Panther pardus) in garhwal Himalayas. Technical report, 2001, WII.

Daniel J.C. (1996). The Leopard India: A Natural History. Natraj Publishers Deheradun, 228p

Eisenberg, J.F. \& M. Lockhart (1972). An ecological reconnaissance of wilpattu national park Ceylon. Smithosonial Contribution on. Zoology. 1001: 1-118.

Guggisberg, C.W.A. (1975). Wild Cats of The World. Davis and Charles, London, 34-67pp.

Henschel, P., L. Hunter, U. Breitenmoser, N. Purchase, C. Packer, I. Khorozyan, H. Bauer, L. Marker, E. Sogbohossou \& C. Breitenmoser-Wursten (2008). Panthera pardus. In: IUCN 2009. 2009 IUCN Red List of Threatened Species. www.iucnredlist.org. Downloaded on 12 November 2009.

Jackson, R. \& D.O. Hunter (1996). Snow Leopard Survey and Conservation Handbook. International Snow Leopard Trust, Seattle, Washington and U.S. Geological Survey, Fort Collins Science Center, Colorado, $154 \mathrm{pp}+$ appendices.

Karanth, K.U. \& M.E. Sunquist. (1995). Prey selection by tiger, leopard and dhole in tropical forest. Journal of Tropical Ecology 64: 439-450. 
Maan, M.A. \& A.A. Choudhary. (2000). Common Leopards our endangered heritage needs special conservation. Tiger Paper 27(OctDec): 4 .

Mizutani, F. (1999). Impact of leopards on a working ranch in laikipia, Kenya. African Journal of Ecology. 37: $211-225$.

Mukherjee, S., S.P. Goyal \& R. Chellam (1994). Standardization of scat analysis techniques for leopards (Panthera pardus) in Gir National Park, Western India. Mammalia 58: 139-143

Pikonov, D.G. \& V.G Korkishko (1992). The Amur Leopard. Nauka, Moscow, 1992pp.

Prater, S.H. (1993). The book of Indian animal, pp.25-42. Bombay Natural History Society, Oxford University Press.

Ramakrishnan, U., R.G Coss \& N.W. Pelkey (1999). Tiger decline caused by the reduction of large ungulate prey: evidence from a study of leopards diets in southern india. Biological Conservation 89: $113-120$.

Seidensticker, J. (1990). On the ecological separation between tigers and leopards. Biotropica 8: 225-234
Shaw, H.G. (1977). Impact of mountain lion on mule deer and cattle in Northwestern Arizona, pp. 17-32. In: Philips, R.L. \& C. Jonkel (eds.). Proceeding of the 1975 Predator Symposium. University of Montana, Missoula.

Shrestha, T.K. (1997). Mammals of Nepal. R.K. Printer, Kathmandu, Nepal, 87-91pp.

Sunquist, M.E. (1983). Dispersal of three radio tagged leopards. Journal of Mammology 64: 337-341

Wegge, P. (1976). Himalayan shikar reserves; surveys and management proposals. Field Document No. 5. FAO/NEP/72/002 Project, Kathmandu, 96pp.

Wegge, P. (1979). Aspects of the population ecology of Blue Sheep in Nepal. Journal of Asian Ecology 1: 10-20.

Wilson, P.N. (1981). Ecology and habitat utilization of Blue Sheep (Pseudois nayaur) in Nepal. Biological Conservation 21: 55-74.

Zhirjakov, V.A. (1990). On the ecology of the snow leopards in the zailisky-Alatau (Northern Tien Shah). International Red Book of Snow Leopards 6: 25-30. 